\title{
矿山地质学的优化与控制
}

\author{
刘有川马侦豪
}

云南金沙矿业股份有限公司因民公司，云南 昆明 654100

[摘要] 针对矿山地质专业涉及的所有理论知识和技能进行全面学习, 并且对矿产资源的研发以及有关方面的最为先进的理论 和行业发展趋势加以了解, 并且能够灵活的利用矿产资源相关管理规范, 来推动各项工作的开展, 相关工作人员需要具备良 好的分析能力以及较强的解决问题的能力。

一、针对工作的目标, 内容进行说明。工作牵涉到的范围, 已经完成地质工作的情况, 所有涉及工作以及既定的效果加以说 明。

二、矿床地质实际情况以及勘探工作所针对的区域的地质情况，勘探技术的利用，勘探工作的实施计划的制定。取样工作的 方法。地质勘测，水文地质以及相关技术标准。

三、施工方案的制定以及施工周期的安排，施工成本的规划，施工物料以及机械的安排等等。

四、针对地质问题需要采用切实的方法来加以解决, 对存储数量的计算方法实施切实的选择, 对后续升级以及存储量加以判 断。

[关键词]矿山地质基础认识; 矿山地质非线性优化; 矿山地质管理

DOI: $10.33142 /$ ec.v2i7.491

中图分类号: U415. 1

文献标识码：A

\section{The Optimization and Control of Mine Geology}

LIU Youchuan, MA Zhenhao

Yunnan Jinsha Mining Co., Ltd. Yinmin Company, Yunnan Kunming, 654100 China

\begin{abstract}
All theoretical knowledge and skills involved in mine geology are fully studied, and the most advanced theoretical and industrial development trends of the development of mineral resources and related aspects are understood, and the relevant management regulations of mineral resources can be used flexibly. To promote the implementation of the work, the relevant personnel need to have a good analytical capability and a strong ability to solve the problem.

1. Description of the objectives and contents of the work. The scope of the work involved, the completion of the geological work, all the work involved and the established effect will be described.

2. The geological conditions of the deposit, the geological conditions of the area to which the exploration work is directed, the utilization of the exploration technology, and the development of the implementation plan of the exploration work. The method of sampling. Geological survey, hydrogeology and related technical standards.

3. The design of the construction scheme, the arrangement of the construction period, the planning of construction cost, construction materials and the arrangement of machinery, etc.

4. In view of the need of practical methods to solve the geological problems, the calculation method of the storage quantity shall be selected, and the subsequent upgrading and the storage capacity shall be judged.
\end{abstract}

Keywords: Understanding of mine geological basis; Nonlinear optimization of mine geology; Mine geological management

\section{引言}

在国内社会迅猛发展的带动下，使得地质行业可以观测以及实施研究的范畴在逐渐的延伸。在空间上，不仅能够 借助直接或者是间接的形式不断的延伸到岩体结构的底部, 并且会对其他星球, 太阳系或者是其他卫星的自身的特定 加以深入的掌握。

很多的相关学科, 诸如: 化学, 生物, 物理等等都在朝着地质学的领域逐渐的渗透, 一些前沿的高科技也被人们 在地质工作中高效的加以利用, 与全面, 深入的田野地质工作相融合, 能够促使人们可以对涉及到的大量的地质情况 和规律进行全面准确的了解。

实验的环境也在不断的高山, 诸如将实验室内的各项设施加以完善, 创造良好的实验环境, 对各种不同的因素加 以模仿等等。并且会将时间因素引入到模拟时间当中。

地质学领域内的理论知识在逐渐的完善，特别是各个陆所给予的有关各类地质的不同阶段的信息能够有效的对大 
陆板块构造理论进行验证，这样就会形成大量的新的知识。

地质学研究的对象市地球。地壳中矿产的形成都和地球表面及其地球内部的地质作用有关。地质学基础知识, 则 重点说明地壳的物质组成、发展变化及其各种矿物产资源的蕴藏规律。通过对各种地质作用、地质现象、地层层序、 矿物岩石、地质构造等的了解，为了掌握成矿理论、矿床类型、矿床水文地质、勘探方法打下基础。

就地质学领域的服务性能来看, 最为关键的内容就是对地球的资源进行不断的研发, 其中涉及到诸多矿产资源以 及新型环保能源。其次因为地区成矿研究的需求, 会对地区地质情况实施全面的分析, 并且带动其他领域融合进来, 促使地质学更加健康稳定的发展。

\section{1 矿山地质基础认识}

\section{1 矿物}

矿物是由地壳中存在的含有特定化学成分 (元素或化合物) 的一种天然起源物。自然界中矿物存在的状态有 3 种: 固态，如石英、正长石、云母; 液态，如水、石油、自然录; 气态，如二氧化碳、硫化氢等。

\section{2 岩石}

\subsection{1 岩石的物理力学性质}

岩石是在各种地质作用下, 由一种或多种矿物有规律地组合成的矿物集合体。岩石的物理力学. 性质表现在其变 形特性、强度特征、破坏形式三方面。

基本要求: 掌握岩石的成分、结构及其力学性质; 了解岩石的变形特征和流变性理解岩石的各种强度及其测定方 法。

重点与难点: 岩石的物理指标、强度及其变形特征, 强度理论。

\subsection{2 岩石的强度特征}

岩石的强度特征是指岩石在受外力作用下发生破坏前所能承受的最大应力, 这个极限就是岩石的强度极限。具体指 标有: 单轴抗压强度、单轴抗拉强度、单轴抗剪强度、三向抗压强度。

\section{2 .3 岩石的破坏形式}

岩石的破坏形式分为脆性破坏、塑性破坏和弱面剪切破坏三种。

（1）脆性破坏：大部分质地坚硬的岩体在特定的环境下都会显示出其具有的脆性破坏的特征, 这也可以说明这些 岩体在外界作用力的影响下不会发生明显的形变以及突发的破坏, 导致破坏的根源只要是因为岩体中存在的裂缝以及 岩体在长时间的外界作用力的影响下所导致的结果。

（2）塑性破坏：在不同方向都存在受力的情况的时候, 岩体结构在受到损坏之前形变情况较为严重, 不会对载荷 造成明显的影响, 主要凸显出的是塑性形变, 结构呈现出流动性, 这种破坏也被人们称之为塑性破坏。塑性形变其实 质就是岩体结构内的结晶逐渐位移的后果，在部分弱结构中这种破坏所造成的结果十分的严重。

（3）弱面剪切破坏：因为岩体成中会存在大量的弱势结构, 进而会使得岩体结构具有一定的不稳定性, 极易在外 界作用力的影响下出现损坏。

\subsection{4 矿层的顶底板岩石}

(1) 顶板岩石: 从采矿工作的角度, 根据顶板岩层变形和垮塌的难易程度, 可将矿层的顶板岩层分为伪顶、直接顶、 基本顶 (又称老顶) 3 种。

(1)伪顶: 是指矿层和直接顶之间极易垮落的较薄岩层。岩性多为碳质页岩或碳质泥岩, 厚度不大, 一般只有几厘 米至几十厘米。它的存在不仅可增加矿石的贫化，而且对支柱支护质量有影响，对生产不利。

(2)直接顶: 直接顶是指直接位于矿层之上, 且在放顶时能及时冒落下来的岩层。一般由一层和几层不稳定岩石组 成。直接顶的厚度为放顶后能在采空区自行垮落的岩层厚度。位于煤层或伪顶之上具有一定的稳定性, 移架或回柱后 能自行塔落的岩层, 且此岩层不存在力的传递。

(3)老顶：是指直接顶上部比较稳固的岩层。它的特点是, 经过几次放顶后, 达到一定暴露面积才冒落。如直接顶 较薄, 老顶在大冒落前会使工作面压力急剧增加, 若管理不善, 可将工作面压垮。对老顶应及时采取措施, 以防事故 
发生。

（2）底板岩石: 矿层的底板岩石可分为直接底及基本底 (又称老底)两种。

(1)直接底: 直接位于煤层之下, 强度较低的岩层。一般由泥岩、炭质页岩、粘土岩等组成, 厚度多为数十厘米, 有的遇水易膨胀，会发生底鼓现象。

(2)老底: 位于直接底之下或直接位于煤层之下, 一般由比较坚硬的砂岩、石灰岩等组成, 对支护的支撑力较强。

\section{3 地层}

地层系统其实质就是针对地层各个层次的空间联系实施说明, 在现实中人们往往利用地层来对单位进行细致的划 分。地质时代其作用是对地层上下层之间存在的关联加以说明。在完成地层结构划分的前提下, 将地壳的发展历程进 行细致的划分。

\section{4 地质构造}

沉积岩层在构成的过程中, 通常都是保持在水平的状态的, 在既定的范畴内是不会出现间断的。但是在随着地壳 运用的破坏, 导致岩体层内部构造以及形态都出现的波动, 这种现场涉及到岩体的形变以及位置移动, 通常被人们称 之为构造变动。构造变动依据形式的不同可以划分为褶皱以及断裂两种形式。人们往往将因为地壳运动而导致的岩体 成的结构的形变叫做地质构造。

\subsection{1 岩层的产状要素}

为了更加详细的对具有一定倾斜情况的岩体结构加以说明, 通常会利用到专业的产状要素来进行说明, 也就是岩 体结构的方向，倾斜方向以及倾斜角度。

(1) 岩体结构方向: 断层与水平面之间的连接线被称之为走向线, 走向线的顺延方向其实质也是断层的延伸方向, 企业可以说明岩体在地表上的延展方向。

（2）倾斜方向：断层机构与走向线形成垂直交叉的线称之为倾斜线，其在水平面上形成的投影所牵涉到的平面朝 下倾斜的情况也是断层的倾斜状态。

（3）倾斜角度: 岩体层结构上的真倾斜线其在水平面上构成的投影之间形成的夹角被叫做倾斜角, 其能够代表纵 向断层面与水平面之间形成的夹角。

\subsection{2 褶曲构造}

褶皱构造上最为基础的参数为褶曲, 其实质就是岩体层的弯曲角度。

(1) 褶曲原始情况：通常将褶曲的原始情况可以划分为背斜和向斜。

（2）褶曲的构成，一个完整的褶曲涉及到多个结构，诸如：中心线，枢纽，翼部等等。

（3）褶曲的种类，结合褶曲的形态可以划分为垂直褶曲，水平褶曲以及倾斜褶曲。

1.4. 3 断裂构造

一般时候，岩体结构在外界作用力的影响下，都会形成机械损坏，进而会导致岩体结构出现一定的形变，可以表 现为出现位置移动, 或者是结构的断裂。在结构发生断裂之后, 两边的岩体如果没有十分严重的位置变化, 可以叫做 裂隙或者是节理。

1) 裂隙

裂隙按成因可分为: 原生裂隙、风化裂隙和构造裂隙。

（1）原生裂隙：是指岩体生成过程中自然形成的裂隙。

（2）风化裂隙：是指岩石在风化营力作用下发生破坏而产生的裂隙。

（3）构造裂隙：是指在地壳运动过程中岩石在构造应力作用下产生的裂隙。

根据裂隙的产状和岩层的产状关系，可分为：走向裂隙、倾向裂隙和斜交裂隙。

2) 断层

岩体结构顺着断裂的方向出现明显的位置一定的断裂情况的话, 被叫做断层。

a 断层要素: 为了对断层结构, 结构形式, 位置移动进行详细的说明, 针对断层内所有的结构给予专业的命名, 这 
些基本结构被称之为断层要素。

(2) 断层的分类: 结合断层各个分层实际异动的情况可以将它们划分为不同的类型, 各个断层其拥有特殊的性质。

(1)正断层: 沿断层面上面的相对下降, 下面的相对上升的断层。正断层主要受到地壳水平张力和重力的作用形成 的。

(2)逆断面: 沿岩层断面上面的相对上升, 下面的相对下降的断层。逆断层主要由地壳的水平应力的挤压形成的.

(3)平移断面: 上下两面只做相对的水平位移这种断层主要由水平剪切作用造成的。

\section{2 矿山地质非线性优化}

（1）在完成前期地质勘查以及地质结构建造工序之后, 借助建造地质环节, 深入的对矿场结构, 矿体岩层的实际情 况, 资源储备量进行全面的了解。准确的掌握需要的各个信息数据, 为后续制定挖掘计划提供支持。在开展施工工作 的时候，需要对地质信息进行不断的完善，这样才能为施工工作给予准确的指导。

(2) 结合相关行政机构指定的相关矿产资源的规定以及技术要求, 需要加大力度来针对矿石的开采贫化损失实施切 实的管控，对于矿产资源需要制定高效的开采和使用规范，对矿石的种类，等级，储备量实施分析研究。

(3) 严格的遵照标准开采流程, 对矿山结合勘测的结论以及资源储备情况依据储备程度三级矿量来实施计算分析, 对矿藏情况的变化加以精准的掌控。

(4) 深入的对地质勘探工作没有涉及到的位置以及在实际挖掘中找到的边缘, 深度的小型矿体资源的存储情况以及 其余主体矿山之间的联系进行分析研究，这样能够有利于挖掘工作的顺利开展。

（5）在实施矿山水文地质工作的时候, 针对矿床结构的地质变化实施分析, 确定对露天以及井巷造成影响的所有的 因素，并且制定水文地质勘察报告，为后期的安全工作的开展以及矿产开采工作给予指导。

(6) 在全面的推进工程地质调查工作的时候, 需要对矿体结构, 地质情况, 露天滑坡实际情况进行了解, 找到因为 资源开采而导致的结构坉塌的根源，确保在实施资源开采工序的时候各项工作能够按部就班的进行。

(7) 对地质勘查以及矿产挖掘工作进行经验总计, 并且实施勘探和挖掘对比, 针对地质情况实施分析研究, 借助生 产地质经验来判断地质勘查工作的结论, 充实地质科学理论知识, 促进矿产挖掘技术的进步。

（8）仔细的针对挖掘工序中涉及到的所有的地质信息资料进行收集整理，制定出严谨的地质勘查报告。

生产地质工作具有良好的综合性, 应该在实际资源挖掘中或者是专业人员的指导下开展, 促进地质勘查, 矿产开 采, 测量工作更好的结合起来。

\section{3 矿山地质管理}

地质管理是其在矿山资源挖掘技术管理领域中作用是十分巨大的，并且这项工作并非是一个短时间的工作，其存 在于矿山位置判断, 矿山勘查, 资源开采的各个工序之中, 保证地质管理工作的效果是所有工作人员最为基础的工作, 地址管理工作对于高效的开采资源，利用资源都是非常有助益的。

矿山地质工作最为重要的工作就是资源的挖掘以及施工服务, 主要凸显在: (1) 针对矿体实施全面的勘察并建造 矿坑矿道, 全面的对矿体实际资源储备量以及资源类型加以了解。这样对于矿产资源的管控工作的开展会给予帮助。(2) 对资源开采工作给予一定的指导，并且在矿体勘探，资源开采以及施工管理工作中也会起到积极的影响作用。(3) 矿 山资源的科学挖掘和使用, 对矿产资源实施检核, 对资源质量进行判断。(4) 针对矿山底部以及周边的矿藏制定开采 技术, 有效的提升资源挖掘效果。（5）针对那些会对矿山安生生产形成一定影响的地址情况实施全面的了解, 并采用 适当的方法加以解决。（6）更好的施展出矿山生产中给予的充足的物料以及各种有利条件, 针对矿山结构地址情况实 施深入的研究分析。

各个阶段在上移阶段工作结束之后, 更加深入的检查在最近一段时间内, 生产地区范围内的地质结构情况, 针对 各个阶段的工作内容和要求具体进行了说明:

(1) 开拓地质其实质就是说在获得开拓扩展工程初步设计信息之后一直到开拓地质报告完成审批的所有工序。

(2) 采准地质其实质就是说从给予采准初期设计信息一直到采准地质说明书审核工作结束之后，涉及到的所有的 地质工作，内容如下: 
首先需要获取工程设计信息，并且需要结合信息制定采准矿体勘探计划。

其次，对各个阶段的所有地质信息实施收集整理，为后期的工作开展给予指导。

最后, 集合信息以及数据来制定采准矿山地区地质说明书。

(3) 回采地质其实质就是说从提供矿山回采设计信息一直到矿山回采地质说明书审批完成为止的过程中涉及到的 全部地质工作，主要有：

首先, 获取回采设计信息, 并在第一时间对矿体挖掘工序获得的信息资料进行收集整理, 为后期挖掘工作给予指 导。

其次，对资料信息加以核对，提升利用效率。

最后，结合获得的信息资料来编制回采地质说明书。

(4) 矿区、矿井或中段即将开采完毕时, 地质测量部门应参与编写闭坑报告。

（5）生产地质勘探，应充分利用采掘（剥）已有工程, 并使探矿工程尽量为今后采矿所利用。可根据矿床复杂程 度、施工技术条件等，选用坑探、槽探、浅井探、钻探和深孔丵岩机探矿。

(6) 地质储量的分级条件, 原则上根据原国家地质总局、国家建筑材料工业总局、石油化学工业部联合发布的《非 金属矿床地质勘探规范总则》执行，但各矿必须根据矿床赋存条件及采掘（剥）工程对矿体（层）控制程度的要求, 对储量分级条件作具体补充规定，报请主管部门批准后执行。

总之, 地质学必须加强基础研究, 如矿物学、岩石学地层学、古生物学等具有奠基意义的学科的研究, 以提高对 各种地质体、地质现象及其形成、演化的认识。同时还要充分吸收和利用其它科学技术的新成果, 包括社会科学的研 究成果, 以更全面、本质地认识地球历史和构造, 为科学的发展, 为人类更合理、有效地开发和利用地球资源, 维护 生存环境, 作出应有的贡献。

\section{[参考文献]}

[1]汪贻水,彭觥, 肖垂斌. 我国矿山地质学新进展 [J].中国金属通报, 2012(2): 17-19.

[2]彭觥, 汪贻水. 新中国矿山地质学的成就 $[\mathrm{J}]$. 矿产勘查, $2000(1): 3-5$.

作者简介: 刘有川, 男, (1980.2.29-) 出生于云南昆明东川, 1997 年 9 月至 2000 年 6 月在原东川矿务局职工中等专 业技术学校读书, 采矿测量专业, 2001 年 8 月至 2008 年 1 月在原东川矿务局因民矿及云南金沙矿业股份有限公司因民 公司工作, 一直从事矿山井下地质工作, 2008 年 1 月至今从事矿山井下地质管理工作。马侦豪, 男, (1987.9. 16-) 出 生于云南省昭通市昭阳区, 2005 年 9 月至 2010 年 7 月在曲靖市云南能源职业技术学院读书, 矿山地质专业 2010 年 8 月至今在云南金沙矿业股份有限公司因民公司工作，一直从事矿山井下地质工作。 